\title{
The Balkans and The Other Heading: Identity and Identification on the Margins of Europe
}

\begin{abstract}
MARINA ANTIC
Rodolphe Gasché characterizes Jacques Derrida's The Other Heading: Reflections on Today's Europe as "an effort that is clearly intent on disputing the New Right's formulation of European identity," an identity based on "cultural self-sufficiency and a nervous nationalism, as has been the case with the French New Right." The occasion for The Other Heading, however, is to be found in the apparent European return to itself in the aftermath of 1989. Derrida writes:

'Reunion' is today an official word. It belongs to the code of French cultural politics in Europe. Ministerial speeches and documents make great use of it; they help explain a remark of François Mitterrand, the President of the Republic, who said (perhaps while also presiding over the European Community) that Europe 'is returning in its history and its geography like one who is returning home' [chez soi]. (8)
\end{abstract}

The jubilant "reunion" has since, of course, become the cumbersome reality of Western Europe taking on "the burden in the East," reluctantly and with many reservations accepting former communist countries one by one into its circle. Disregarding for the moment the somewhat ugly reality of this forecasted "reunion," we should ask ourselves what it means to foreground this important moment in the relationship of Western Europe to Eastern Europe in an essay challenging the very notion of identity in general and European identity in particular. What effect, if any, would an Eastern European perspective have on the arguments in such an essay? Can we locate Eastern Europe in the text that is occasioned by its apparent meld into a common European identity? What effect, if any, do Derrida's claims in The Other Heading have on Eastern Europe and its identity? 
In searching for answers to these questions I will also attempt to answer a more fundamental problem in reading Derrida's The Other Heading from an Eastern European or, more precisely, Balkan perspective: Is there common ground between Derrida's interrogation of identity in general and European identity in particular and the critique of Europe posed by Balkan intellectuals over the past twenty years? This question is a reformulation of R. Radhakrishnan's line of argument in "Postmodernism and the Rest of the World" where he asks: "Is there common cause between the interrogation of modernity within the developed world and Third World critiques of modernity? Are there sharable issues, agendas and objectives between these two constituencies despite the fundamental asymmetry that sustains East-West relationships?" (308). Therefore, what follows is, in short, an application of Radhakrishnan's argument in "Postmodernism and the Rest of the World" to a Derridean (dis)engagement with Eastern Europe. In that sense, it is an exercise of sorts, an attempt at applying achievements in postcolonial theory to the reality of Eastern Europe and as such represents less an original contribution than an attempt at redirecting our understanding of Derrida's and Radhakrishnan's arguments from an Eastern European perspective. In addition, I use Alexander Kiossev's argument about Balkan identity as an example of a way we can perceive Eastern European (or at least Balkan) identities that does not fit the Derridean mold. As one final caveat, then, I note that I subscribe to Kiossev's argument only provisionally and present it here more for the sake of demonstrating the fallacy of Derrida's view than for the sake of arguing for its validity per se.

Derrida's argument for salvaging the idea of Europe (or European identity) centers on the possibility that Europe can be understood as "the opening onto a history for which the changing of the heading, the relation to the other heading, or to the other of the heading, is experienced as always possible" (17). The "heading" Derrida speaks of is, first, an idea of Europe as a heading, a cape, an appendix to the Asian body (21) and, secondly, a heading that is not Europe, that is, other to Europe, but one that is in its otherness also constitutive of European identity. In other words, on the one hand, Derrida recalls the structures of imagination that identify Europe as a heading: "an advanced point of exemplarity," a "figure of the Western heading and of the final headland or point," "a heading for the universal essence of humanity." On the other, in claiming that "what is proper to culture is to not be identical to itself," Derrida establishes the significance of the (colonial) other in the notion of the 
(European) self. This is what Gasché calls a difference with itself "that derives from identity's continual reference to the identity of other cultures over and against whom any self-identity is established" (126).

Regarding this formulation of the heading of the other, Derrida redefines European identity as a radical responsibility for itself, that is to say, a necessity of Europeans reminding themselves of the heading of the other, "before which we must respond, and which we must remember, of which we must remind ourselves" (15). This necessity of reminding themselves of the other is fundamental to the new Europe Derrida imagines, a Europe beyond Eurocentrism and anti-Eurocentrism, a Europe that is the very possibility of changing the heading and the relationship to the heading of the other.

At the same time, I would add, the notion that it is necessary to remind yourself of the other is a decidedly European notion, and an "old" European notion at that. For the other or, more precisely, the European other (the other of Europe) is precisely the very impossibility of this "remembering" or "reminding." The (post)colonial subject cannot "remind" herself of an "other" precisely because she has no "other" that is not ever-present in her notion of self. One can, naturally, remind oneself of something only if that something is absent. (Post)colonial identity, however, always presupposes the presence of the European and his "otherness" from the native.[1]

The same holds true for Balkan identity. To identify oneself as Balkan means precisely to identify oneself over and against Europe, the Western heading, the heading for the universal essence of humanity. In such a process of identification Europe does not occupy a space of just any other culture over and against which one defines oneself - it occupies the space of the universal, the essential.

Further, Europe's imagination of the self as a heading, and especially as the heading for the universal essence of humanity, is not only an epistemological structure. Nor is it only implicated in the history of modernity and colonialism, in the sense that modernity or colonialism have tainted its meaning. More fundamentally, this structure of Europe's imagination is part and parcel of Europe's colonial, material history. Identification and relationship of oneself to an other does not, after all, happen in a vacuum, but is conditioned by history. The fact that Europe "knew" the other through dominance cannot, therefore, be erased by an epistemological break from this history alone.[2] The fact that Balkan identity is always already reminded of this material and epistemological dominance is not mere provincialism or a wounded 
sense of marginality. Rather, it is a reflection of the empirical conditions that, at least in part, determine or have historically determined local knowledges and identifications.

However, the process of Balkan identifications is also more complex than this. Within the space dominated by the West and the Western gaze, Balkan identity also captures what we can call an understanding of the self through a series of reflected gazes: West to East and back. In other words, the Balkan self comes into being and exists in the space inbetween East and West so that what it means to be Balkan has meaning only within the realm of reflected perceptions and self-perceptions, not any stable, geographically or philosophically fixed phenomena. In this, the Balkan self is never separate from the European gaze and Europe is thus never absent from the Balkan self-identification.

Alexander Kiossev details this process of self-identification through a Lacanian prism in "The Dark Intimacy: Maps, Identities, Acts of Identification." He argues that the Western perception of the Balkans - a discourse known as (Western) Balkanism - was of critical importance in the mapping of identities in the Balkans. The cultures of the official Balkan nation states have "for decades, if not centuries, attempted to escape the image of the "dark Balkans'" (180). There were persistent attempts at differentiating oneself from others in national and cultural discourses of the Balkan nation-states, but these attempts always encountered the uncompromising Western gaze intent on erasing any signs of difference, perceiving the region "from a macro-colonial perspective." As a result:

Internalizing both the emotional trauma of non-recognition (public and historical invisibility) and the moral one (failure to fulfill the supposed historical duty), the ideologies and high cultures of South European nations have always harbored an obsessive concern. They tried to compensate for their geo-political and geo-cultural irrelevance with certain ideological self-representations. [...] Thus, for the national ideologies of the Balkan countries, different as they were, the Balkans also had a hidden, dark, mythological aura. [It] signifies the melting and disappearance of the national subjectivity before the gaze of the 'Significant Other.' [...] Being a traumatic mirror-discourse, the 'native' Balkanism seems to share the same stigmatizing series of predicates as the Western one but associates them with different emotional nuances: at times, anger and aggression against the Significant Other; at times, with failure and shame, even self-disgust. (180-82)

The Balkan identity thus fluctuates from non-recognition and irrelevance to native ideological self-representations as stages of a "mirrordiscourse." The flux Kiossev sees between the Lacanian mirror stage and 
the symbolic stage ("static forms of symbolic 'identity' are not permanently fixed, signifiers (identity models) float and change, libidinal investments and acts of identification continue") he then applies to the cultural sphere and perceives a dialectical exchange in the formation of Balkan identity.

The imposition of a "stable" identity onto the Balkans, whether that imposition comes from within or from the West, produces two major forms of identification: "the first option is to leave, to escape, to cast off the unbearable 'armor' of the imposed identities"; the second, an escape into "passionate nationalism and hyperbolic pride" (182). It becomes clear, then, that stable identities imposed from without or ideological self-representations fueled by the disappearance of national subjectivity before the European gaze invoke different identifications intent on answering or challenging this "traumatic mirror-discourse." What is also quite clear from Kiossev's argument is that the resultant Balkan identity is never separate or formed without not only the presence of Europe, but also a self-conscious awareness of that presence.

This example of the Balkan processes of identification hopefully clarifies why to insist on the necessity of reminding oneself (as a European) of the other is to reaffirm Europe's dominance in this refraction of identities across East-West boundaries. To "remind" yourself of the other is, at the same time, to reclaim the privileged position of an identity that believes it has a choice to be defined or not defined by others, regardless of whether such an ideological position is actually sustainable or not.

But Derrida also speaks of Europe as a possibility of an opening to the other of the heading. This is what Gasché calls an internal difference of "any identity not from the state of non-identity, from which it had to be wrenched, but with a 'state' anterior to the difference of identity and non-identity" (126). Gasché paraphrases this part of Derrida's argument in the following way:

But [Europe] must further recall, and recall itself to that which, while not being its opposite - headlessness, and a drifting without direction - is no longer of the order of the head and of a heading, but is the very thing from and thanks to which the binary opposition of heading and the other heading, of self and other, of identity and non-identity, can distinguish their meaning. (127-28)

In other words, that which makes identification possible but is itself beyond identity and non-identity alike is another necessary "other," of which Europe must remind itself and to which it must aspire in selfidentification. Where does this need for an ultimate "other" - the other of 
Identity for which Europe ultimately stands as the supreme example come from? Why is the new Europe Derrida aspires to in The Other Heading tied to the notion of a beyond identity and non-identity?

For one, Derrida claims that "Old Europe seems to have exhausted all the possibilities of discourse and counter-discourse about its own identification" (26). In other words, for Europe the discourse of identity (and non-identity) seems to hold little promise. Further, however, Derrida claims that the rejection of this apparently exhausted discourse of identity applies to "identification in general":

Dialectic in all its essential forms, including those that comprehend and entail anti-dialectic, has always been in the service of this autobiography of Europe, even when it took on the appearance of a confession. For avowal, guilt, and selfaccusation no more escape this old program than does the celebration of self. Perhaps identification in general, the formation and affirmation of an identity, self-presentation, the self-presence of identity [...] always has a capital form, the figurehead [figure de proue] of the advanced point, and of capitalizing reserve. (26-7)

Before engaging the notion of this state anterior to identity and nonidentity, I must first comment on Derrida's universalization of his argument to include all identity. The above argument about the radical responsibility new Europe will take on hinges on the observation that the avowal, guilt and self-accusation Europe has purportedly hurled upon itself in recognition of its sordid history is as impotent and self-serving as its glorification. In terms of a philosophical redefinition of the European self, this might hold up as a valid argument. And perhaps in terms of European self-perception, this avowal, guilt and self-accusation do not, in fact, promise a future for Europe. But, in terms of those on behalf of whom Europe experiences this guilt and self-accusation (the other heading), the difference between self-criticism and celebration of the self is immeasurable. Imagine if this guilt and self-accusation were actually allowed to take root - they might just have produced an agreement, a European agreement to forgive the Third World debt and pay reparations to Africa. This, I propose, would for once not be the same "old program." [3]

But within Europe proper, the dialectic and the anti-dialectic, according to Derrida, have played out their roles, serving Europe in its innumerable autobiographies at the expense of the other. Let us, for the sake of argument, take this as true, namely that the dialectic (and antidialectic) has nothing to say to Europe any longer and that all its programs have all been played out ad nauseam. Let us also assume that 
identification based on these programs has long proven to be impotent in Europe. How does this translate into a claim that identification in general is also implicated in this proverbial beating of a dead horse?

It is unlikely that Derrida made a typically European error of generalizing from a European reality onto a universal realm. Rather, a structure of domination that is much harder to pinpoint and eliminate than a simple error of prejudice or Eurocentrism is on display here. R. Radhakrishnan speaks to this structure of domination as follows:

Given the avant-gard-ism of the West, it is only inevitable that the very regionality of western forms will travel the world over as dominant-universal forms. In other words, western realities have the power to realize themselves as 'general human conditions.' The passage from specific reality to a general condition is effected through the mediation of knowledge and epistemology. [...] It is the ability of the developed world to conceptualize and theorize its particular organic empirical reality into a cognitive-epistemic formula on behalf of the entire world that poses a dire threat to other knowledges. [...] Thus a report on the epistemology elaborated in the metropolis either begins to speak for the human condition the world over or assumes a virtual reality to be devoutly wished for by the rest of the world (308).

That is to say, Derrida's projection of a hypothesized European reality (the overused, impotent dialectic and anti-dialectic) becomes a matter of a cognitive-epistemic formula on behalf of the entire world, namely: identity as such should be abandoned for identification in general is an impotent, "traditional discourse of modernity" (28). After all, how could anyone still be interested in modernity, the source and rationale for the domination of much of the world by the European? The interrogation of identity Derrida takes up here is, thus, always already determined when it reaches the Third World, the Third World has no say in its "theorization into lexical significance" and it thus becomes a general human condition, not least because of the location where such theorizing takes place. The lingering question of whether it is still possible to find common cause between Derrida's critique of European structures of identity and the Third World's critique of the same despite these power dynamics will be addressed later.

Derrida argues further that his vision of a new Europe is a new type of responsibility: "Identity would thus be instituted in responsibility, which is to say - and we will come back to this - in a certain experience and experiment of the response that here bears the whole enigma" (52-3). The responsibility in question is the responsibility to, for and before the European identity's claim to universality - precisely because it was in the name of Europe that the concept of universality appears. To claim 
responsibility in such a radical sense (opening oneself not only to the other but to the other of identity itself) is especially effective in the sense that Derrida's reworking of European identity does not abandon Europe's epistemological burden toward the other. As Gasché says:

Indeed, to use the name 'Europe' as a denomination for the responsibility in question is to engage the Europeans, first and foremost, in that responsibility. Calling it by that name is a performative, a first singularization of this responsibility, one that is binding and that calls European to respond to its call insofar as they are European, that is, the inheritors of a mode of thinking that sought universality from the start (143).

However, Derrida's project does not end here. He goes on to argue that the claim to universality is paradoxical in two ways: first, as it is "no less constitutive of the essential or constitutive traits of French consciousness" and secondly, because this feeling of "being "men of universality'" is not reserved for the French or Europeans, but extends to all forms of identification. Indeed, Derrida writes that:

Whether it takes a national form or not, a refined, hospitable or aggressively xenophobic form or not, the self-affirmation of an identity always claims to be responding to the call or assignation of the universal. There are no exceptions to this law. No cultural identity presents itself as the opaque body of an untranslatable idiom, but always, on the contrary as the irreplaceable inscription of the universal in the singular, the unique testimony to the human essence and to what is proper to man (73).

This is how Derrida extends his argument about the processes of European identification onto all claims to identity. And as we have seen earlier, identification, according to Derrida, also always involves not only the self, but consciously or not, the other and the other of the self/other division. But, unlike Gasché, who sees in this no imposition upon the other (131), I argue that Derrida here fails to see how, first, his argument is necessarily imposed upon the other and, second, how his claims about identity and identification actually reaffirm the European irresponsibility tow ard the other.

As mentioned earlier, due to the geo-historical situatedness of Derrida's argument, it is almost impossible to write from a theoretical position in Europe without running the risk that the "report on the epistemology elaborated in the metropolis [will] either begin to speak for the human condition the world over or assume a virtual reality to be devoutly wished for by the rest of the world." But once the conclusions of the critique actually extend to all identification, as in our example, this possibility of an imposition upon the other becomes a reality. Because 
theory elaborated in the center, under economic and material circumstances of European (or Western) dominance of the world, tends to reaffirm the dominance of Western episteme at the expense of local knowledges, Derrida's claims about identity actually reaffirm European hegemony in both epistemological and material terms. Further, proclaiming all identity, without exception, to be implicated in this will to universality, without input from "the other shore," without even a consideration of the closest example - the one that occasioned his essay namely, Eastern Europe, is the prolongation of the irresponsibility with which Europe has thought of itself for centuries.

Again taking the example of the Balkans, I argue that Derrida's vision of the radical openness to the other (and to the other of the identity/non-identity division) as a model for identification is not borne out by the example of his analysis, nor is it applicable to identity in general. And neither is the claim that every self-affirmation of identity is always a response to the call or assignation of the universal.

Above I quoted Kiossev's analysis of Balkan identity and the responses to the imposition of "stable" identities through two common forms of (dis)identification: an escape, a "radical emigration, close to cultural amnesia"; and a retreat into hyperbolic nationalism. But Kiossev very insightfully notices an opening in the "Balkan patchwork and the above-mentioned cognitive dynamics" that while discrediting the national, the European and the universal also allows for "the contemporary everyday life of the peninsula [to] repeatedly display the old-new plethora of pre-modern, modern, and post-modern similarities and differences" (184). His argument can be summarized as follows.

Society and culture in the Balkans (and presumably beyond) create a lot of opportunities for identification. (Identification, for Kiossev, is that moment of recognition of the self in (an) other, regardless of whether that recognition is an occasion for joy or sorrow.[4]) At the same time, society tries in various ways to force the individual or a group to assume a certain "stable" identity, a rigid structure, a fixed and stable totality. In the dynamic flux of identity (stable, rigid, national) and identification ("a-ha" moments) we are faced with a lot of overlapping cognitive maps and a multitude of possible or actual identities with competing cognitive strategies. In such a context, the acts of individual identification are performed not against stable identities but rather they take place in an unstable field, where various identity models are competing, contradicting and transforming one another. In the Balkans, this field consists roughly of pre-modern identities, Western perceptions of Balkan 
identities and self-representations (national or otherwise). Individuals can choose among the dominant identity models (escaping the Balkans in disgust or retreating into rabid nationalism), but the Balkan patchwork also opens a free space for them to react differently: to have multiple "a-ha" experiences, alternative identifications and counteridentifications, etc.

What Kiossev goes on to call "a new type of arrogant Balkan intimacy" indicative of this Balkan patchwork is best captured in the nostalgic, but ironic and at times taunting, tone of Emir Kusturica's films.[5] Characters whose violence, sexuality, cruelty, uncontrolled passion, barbarism, ignorance, and arrogance seem to outdo the very stereotypes that identify them as such help create a cinematic Balkan world speaking to both the imposed "stable" identities and the rebellious identifications over and against such identities.

Take, for example, one of the last scenes from Underground, where against the backdrop of a fanatical ethnic war, a conversation takes place between a United Nations "blue helmet" representative and the character Blacky. We have just learned that Blacky is on a murderous, fanatical mission of killing or capturing enemies from all sides: Ustashe, Chetniks, UN personnel, and last but not least war profiteers. The UN representative addresses Blacky:

- Protestujem gospodine! (I protest, sir!)

- I ja protestujem druže! (I also protest, comrade!)

- Nisam ja drug gospodine. (I am not a 'comrade', sir.)

- Nisam ni ja gospodin druže. (I am not a 'sir' either, comrade.)

- Ko ste vi: ustaša, četnik, partizan? (What are you? An ustasha, a chetnik, a partisan?)

- Ja sam Petar Popara Crni. (I am Petar Popara Blacky.)

- Kojoj vojsci pripadate druže? (To which army do you belong?)

- Mojoj. (My own.)

- Ima li neko iznad vas? (Is there anyone above you in rank?)

- Ima, moja zemlja. Jebem li ti mater fašisticku. (There is. My country. Fascist motherfucker.)

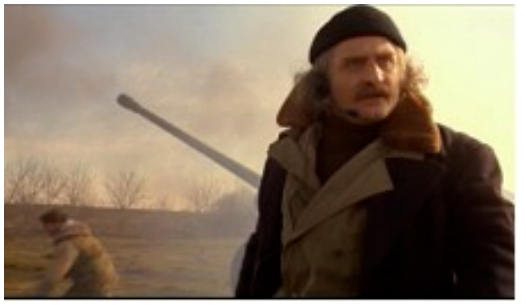

Blacky firing at "all enemies."

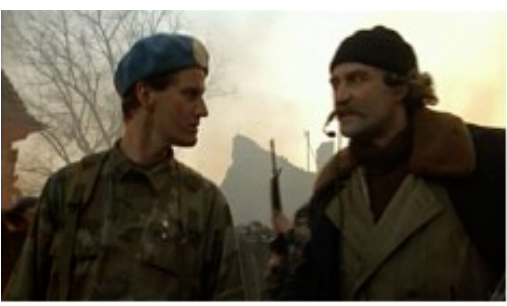

Blacky and the UN "blue helmet" speak. 
"There is. My country."
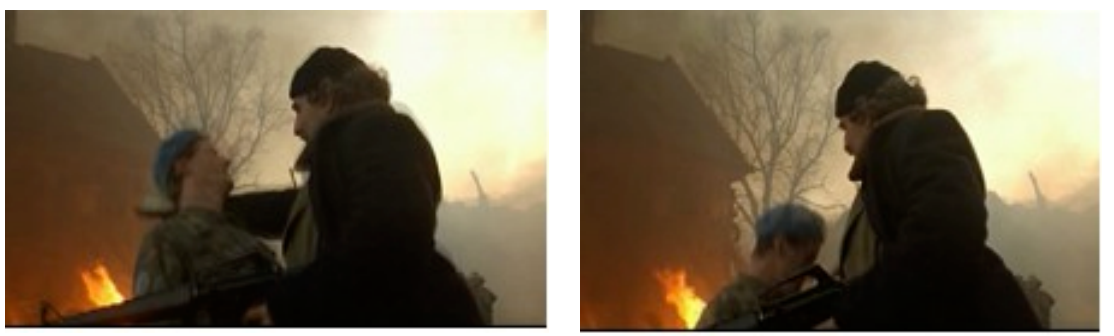

Blacky knocks out his opponent, Balkan style.

Blacky's violence is both an intensified version of the Western stereotype of the Balkans and an embodiment of the despair from which a rejection of this imposed identification arises. His refusal to adapt to the reality of the jubilant "transition" to Europe evident from his insistence on being addressed as "comrade" is characterized both by his (dis)identification from the newly imposed ethnic realities and his refusal of Western codes of conduct. Compare Blacky's verbal and physical defiance in the face of imposed identities to earlier responses to the same problem of Balkan identities in scores of Ivo Andri 's "small people," whose lives hint at defiance only by their mute insignificance.[6] Kiossev explains Blacky's behavior and the popular identification with his character in the following way:

[A] Balkan popular (counter) culture was born in all the Balkan countries: a new mass taste for the old belly dance developed, [...] a new type of arrogant Balkan intimacy haunted the air. The most important symptom of this process was the lack of popular will to be Western-like (a rejection of not only the current political slogan 'on the way to Europe,' but also of the old Balkan perception of the West as a kind of secular transcendence). [...] It turns the lowermost picture of the Balkans upside down and converts the stigma into a joyful consumption of pleasures, forbidden by European norms and taste (184-5).

This is the opening in the aforementioned Balkan cognitive dynamics of identifications and the strongest argument against Derrida's claim that to overcome the exhausted discourses of identification, a new radical openness to the other of identity and non-identity is necessary. For the Balkan "cognitive dynamics" the question of identity is not a question of overcoming the dialectical exchange between self and other or identity and non-identity precisely because the identifications and (dis)identifications in the Balkans are rooted in the exchange of identities across the East-West boundary, not within them. The European can and does identify himself within a space that is at least ideologically 
constructed as closed off from the other. The Balkan states could not sustain this ideological claim to a stable, differentiated identity. As Kiossev says "the ideologies and high cultures of South European nations have always harbored an obsessive concern" about their authenticity and difference precisely because the intrusion of Europe (in the form of a material and critical knowledge of the Balkans from a colonial perspective) could not be successfully hidden in nationalist claims. That is to say, even when celebratory of national identities, the Balkanites are always already also disappointed with them. Identity is always already challenged in the Balkans, not least because of its position towards the stable even if negative European selfidentifications. Because of this, it never took on the simplistic forms of celebration or self-avowal as two poles of its identity, and thus, the proposed escape from these structures does not correspond to the reality in the region.

While other intellectuals have struggled with understanding and stabilizing this marginal identity, Kusturica's expression of this contemporary popular trend in Balkan identifications represents, for the Balkans, an opening akin to what Derrida imagines for the European.[7] What this new Balkan identification offers is a way of taking responsibility for and before the Balkan "identity" recognizing both the internal and external impositions of such an identity but also moving beyond the exhausted nationalist rhetoric or self-imposed cultural amnesia. In this, perhaps, is one point of common interest: namely, to move beyond our current patterns of identification in both Europe and the Balkans.

But, unlike Europe, the Balkans cannot and should not define themselves as a "sentiment of this necessity that all claims to identity and universality require [... an opening ] to [something] other than the opposition of the Western and the non-Western" (Gasché 144). For, the Balkans, willingly or not, already occupy a space where the Western and the non-Western are demystified as a series of reflected gazes. To be Balkan today is precisely to acknowledge these hegemonic, constructed identities and rather than finding a "third" way beyond them and their negations, engage them to the point of absurdity. This is perhaps the only way to disarm them from a marginal position.

The significance of these observations about Balkan identities to Derrida's new Europe is not immediately apparent. Beyond being an empirical example of a counterargument, the Balkan case also shows that Derrida himself fails to open up the very text (in which he professes 
such a radical openness to the other) to the other of the European understanding of identity, namely that of Eastern Europe. The absence of Eastern Europe in the text is, in fact, glaring. Is the radical responsibility for and to the other just another example of what Radhakrishnan so correctly described as an impotence of the self-critical West? "Withdrawing from its sorry history of knowing the Other through dominance, a self-critical Eurocentrism abandons the Other altogether in the name of non-interference. [...] The Other becomes the burden of the Self's negativity, a negativity produced by the Self through its own autocritical - deconstructive engagement with itself" (309).

Perhaps Derrida would argue that his insistence on engaging with identity as such and asserting that any self-identification carries with it a claim to universality does in fact incorporate or bring the Other into the realm of his argument and perhaps even into a relationship with Europe that is not one of dominance. For, if all identities do, in fact, suffer from this claim to the universal, Derrida's argument might be of benefit to them as well. But the claim that any self-identification is always already a claim to hegemony or universality is itself suspect. Again, let us take the example Derrida chose not to engage: the Balkans. Can we say that a Balkan identity is always already a response to the call or assignation of the universal?

For Derrida, identity can either be a "response to the call of the universal" or a presentation of itself as "an opaque body of untranslatable idiom" (73). But, in reality, the field of identifications is usually much more complex than this and claims neither universality nor untranslatability. The "new" Balkan identity evident in Kusturica's films or Goran Bregović's music or a host of other popular identifications arises not as a claim to the universal, but as a challenge to identities that map themselves out from nation to Europe to the universal. This new popular consciousness does not celebrate its new identity as anything standing on its own, outside of a complex web of relationships to the West and East and thus claiming exemplarity and universality. Rather, it celebrates, perhaps too jovially, the perception of the Balkans "as they are: backward and Oriental, corporeal and semirural, rude, funny, but intimate" (Kiossev, 185). But it is also not "an opaque untranslatable idiom." In fact, it is the most translatable, the most understandable of all Balkan identities so far because it speaks from within the space imagined by the West, in the West's idiom, even if only to "scandalize the "civilizational standards"' all the while retaining all of the characteristics of a "Balkan neighborhood." The 
result is a "trickster-like, comic, and aggressive transformation" of identity that doesn't speak to a will to the universal, except perhaps as it mocks it in its European alter-ego.

In conclusion, let us return to the question of whether common ground can be found between The Other Heading and the critique of identity we find in recent trends in both Balkan scholarship and the Balkan popular imaginary. Besides challenging Europeans to consider the contribution to the discussion of Identity from the margins, cultural theory coming from the Balkans and its post-1989 diaspora is an example of how a response to the epistemological dominance of the West does not always have to include a resignation to the European intellectual trends. While maintaining that Derrida's answer to the history of identification and identity patterns in Europe is inadequate as a model for all identity and is lacking even as a performative call to a new Europe, the intent and seriousness with which he approaches European responsibility towards the other can only benefit the debate on identity in Balkan scholarship.

NOTES

[1] I am taking this ever-present European other in the native in a limited sense because an argument could be made that the postcolonial (as opposed to the colonial) identity is precisely an assertion of agency separate from the identity of colonial domination. However, in theory, only a post-imperial identity could be fully separate from any references to the (European) colonial other.

[2] Radhakrishnan also makes a similar point. In addition, while I am aware of the deconstructionist contention that there is no binary opposition between the textual (or epistemological) and reality, I would contend that while we can perceive the textuality of everyday life we can also understand that how we perceive the effect of everyday life on us is not only textual (there is, after all, something very non-textual in our perceptions of the most extreme intrusions of the world upon our person, like getting shot or beaten).

[3] I am thinking here of, I believe, a comparable example from European history, namely the aftermath of World War II. While we can agree that an argument that would paint Nazi terror as an aberration of "European" history or that would attempt to rationalize or categorize the Holocaust in any other way is ultimately opening Europe to the possibility of repeating this history, I would still argue that reparations for forced labor and Holocaust crimes is still a significant element of Germany and Europe coming to terms with this history.

[4] He uses the example of a Balkanite encountering, somewhere in Western Europe or the US, another Balkanite and despite all apparent differences, having an "aha moment" of recognition in that other person.

[5] Not to be outdone by his characters, Kusturica, allegedly, attended the Cannes film festival, where he incidentally won Palm d'Or for his masterpiece 
Underground, drunk and followed by a (typically Balkan) brass band playing loud gypsy music to the chagrin of the organizers and the red carpet elite.

[6] See especially The Bosnian Chronicle for exchanges between Westerners and locals.

[7] It is worthwhile noticing that Kusturica himself is an atrociously bad example of how to go about this. His Serbian nationalist histrionics (mostly choreographed for shock value itself) only alienate those on whose behalf his characters speak. That should not prevent us from considering his films as instructive of Balkan reality even if his public persona is a vulgarized version of the same.

\section{WORKS CITED}

Derrida, Jacques. The Other Heading: Reflections on Today's Europe. Bloomington: Indiana University Press, 1992.

Gasché, Rodolphe. "Feeling the Debt: On Europe." Future Crossings: Literature Between Philosophy and Cultural Studies. Evanston, IL: Northwestern University Press, 2000. 125-46.

Kiossev, Alexander. "The Dark Intimacy: Maps, Identities, Acts of Identification." Balkan as Metaphor: Between Globalization and Fragmentation. Ed. Dušan I. Bjelić and Obrad Savić. Cambridge: MIT Press, 2002. 165-90.

Radhakrishnan, R. "Postmodernism and the Rest of the World." Organization 1: 2 (1994): 305-40.

Underground. Dir. Emir Kusturica. New York Video, 1995. 
